\title{
Best Practices for the Orthopaedic Care of Children with Spinal Muscular Atrophy: A Consensus Statement from the European Neuromuscular Centre Standard of Care Orthopaedic Working Group
}

Michael Vitale, $M D, M P H^{1, a}$; Benjamin Roye, $M D, M P H^{1}$; Zachary Bloom, $M D^{2}$; Jennifer A. Kunes, $B A^{1}$; Hiroko Matsumoto, PhD ${ }^{1, *}$; David Roye, $M D^{1}$; David Farrington, $M D^{3}$; Jack Flynn, $M D^{4}$; Matthew Halanski, $M D^{5}$; Carol Hasler, MD ${ }^{6}$; Lotfi Miladi, $M D^{7}$; Susana Quijano-Roy, $M D^{8}$; Christopher Reilly, $M D^{9}$; Paul Sponseller, $M D^{10}$; Muharrem Yazici, $M D^{11}$; Brian Snyder, $M D, P h D^{12, a}$

${ }^{1}$ Columbia University, New York, NY, U.S.; ${ }^{2}$ University of Massachusetts, Worcester, MA, U.S.; ${ }^{3}$ Hospitales Universitarios Virgen del Rocío, Seville, Spain; ${ }^{4}$ Children's Hospital of Philadelphia, Philadelphia, PA, U.S.; ${ }^{5}$ University of Wisconsin, Madison, WI, U.S.; ${ }^{6}$ University Children's Hospital Basel UKBB, Basel, Switzerland; ${ }^{7}$ Necker-Enfants Malades, Paris, France; ${ }^{8}$ Centre de Référence Maladies Neuromusculaires, Garches, France; ${ }^{9} B C$ Children's Hospital, Vancouver, $B C, C A$; ${ }^{10}$ Johns Hopkins Medical Center, Baltimore, MD, U.S.; ${ }^{11}$ Hacettepe University, Ankara, Turkey; ${ }^{12}$ Harvard Medical School, Boston, MA, U.S.

Correspondence to: Hiroko Matsumoto, PhD, Division of Pediatric Orthopaedic Surgery, Columbia University Medical Center, 3959 Broadway, 8 North, New York, NY 10032, E-mail: hm2174@cumc.columbia.edu

${ }^{\mathrm{a} C o-c h a i r}$

Received: January 3, 2022; Accepted: January 3, 2022; Published: February 1, 2022

DOI: 10.55275/JPOSNA-2022-0006

\section{Abstract:}

Spinal muscular atrophy (SMA) is a genetic disease resulting in orthopaedic problems that warrant intervention. Recent genetic therapies appear to improve the natural course of this disease, prompting care providers to rethink treatment strategies. Insufficient high-quality evidence exists to guide optimal intervention in this new landscape. To address this, the European Neuromuscular Centre (ENMC) tasked an orthopaedic subgroup to update previous recommendations. A consensus statement on orthopaedic treatment of patients with SMA undergoing genetic therapy was sought via Delphi method. After review of the orthopaedic literature, three iterative surveys were administered from 2015-2016 to worldwide experts in orthopaedic care of children with SMA. Surveys identified important topics for optimal management, solicited responses regarding management and evaluation of identified topics, and clarified decision-making 
strategies and indications for evaluation and management, respectively. In light of new evidence of the long-term effects of gene therapy on SMA patients, an additional review of literature was used to contextualize the consensus recommendations.

Thirteen experts on orthopaedic management of SMA identified treatment of spine deformity, hip instability, and joint contractures as issues of importance. Experts recommended instrumentation in spinal deformity for major curves greater than 50 degrees, while monitoring pain, respiratory function, kyphosis, pelvic obliquity, functional status, trunk imbalance, and rib deformity. Preferential use of magnetically controlled growth constructs and performance of final fusion with skipped levels to accommodate intrathecal access were also endorsed. Additionally, experts advocated for surgical correction of hip instability and/or contractures that cause pain or functional impairment.

\section{Level of Evidence: Level IV}

\section{Key Concepts:}

- Almost all patients with spinal muscular atrophy (SMA) develop scoliosis and most undergo scoliosis corrective surgery.

- Recent innovations in treatment for SMA necessitate re-evaluation of best practice guidelines based on the changing prognosis of these patients.

- A panel of worldwide experts in the orthopaedic care of children with SMA convened to develop a consensus on best practices in orthopaedic treatment of SMA patients in the era of gene therapy.

\section{Introduction}

Spinal muscular atrophy (SMA) is a genetic disorder that results in atrophy and progressive weakness of the truncal and peripheral musculature, occurring in 1 in 11,000 births. ${ }^{1,2}$ SMA is caused by loss-of-function variants of the survival motor neuron 1 (SMN1) gene, leading to under-expression of the survival motor neuron (SMN) protein and subsequent degeneration of motor neurons in the spinal cord and lower brainstem. ${ }^{3-5}$ In recent years, the intrathecally administered anti-sense genetic therapy Spinraza ${ }^{\circledR}$ (nusinersen: Biogen, Cambridge, MA, U.S.) has demonstrated the ability to slow the progression of symptoms. ${ }^{6-10}$ FDA trials demonstrated improvements in quality-of-life scores, progression and maintenance of motor milestones, and substantially fewer incidences of motor function regression versus control groups, which led to its accelerated approval as the first drug to treat SMA. ${ }^{7-13}$
The natural history of SMA is grim. The genetic etiology of SMA involves the survival motor neuron-1 (SMN1) gene; affected individuals have a homozygous SMN1 deletion, mutation, or combination of heterozygous deletion and mutation of the remaining SMN1 copy. The SMN2 gene also produces a smaller amount of SMN protein, and in individuals with SMA, the SMN2 copy-number influences phenotypic severity. Clinically, SMA is classified into four types by age of symptom onset and severity. SMA1 presents at age less than 6 months and results in severe muscle weakness, often resulting in inability to sit unsupported, and weak respiratory clearance leading to early mortality. SMA2 presents at ages between 7-18 months with delayed motor milestones and inability to walk independently. SMA3 presents later in age with loss of the ability to walk independently in childhood and adolescence. 
SMA4 often presents later in life and results in mild motor impairment. ${ }^{14,15}$ Musculoskeletal ailments are very common, with recent surveys indicating that the majority of children with SMA experience at least intermittent back, hip, groin, and/or foot pain. The same survey found that a large proportion of these children have undergone scoliosis corrective surgery. ${ }^{16}$ The evidence supporting this procedure in patients with SMA is well documented. ${ }^{17-23}$ Hypotonic spinal curves continuously progress through childhood, and because conservative management is often unable to halt curve progression, spinal instrumentation is frequently indicated to preserve truncal balance, respiratory function, and quality of life. ${ }^{17,22-32}$

Though treatment of spinal deformity is well-established, operative management of hip instability has not generally been recommended based on the historically high probability of recurrent instability. ${ }^{33-35}$ While hip instability is common in this population, hip subluxation rarely causes pain, and surgically stabilized hips often re-dislocate. ${ }^{33,35}$ Thus, while historic data does not support surgical management of hip pathology, the changing presentation of SMA in light of new genetic treatment strategies calls into question whether more aggressive management is indicated to optimize function for patients with increased motor strength and stamina after genetic treatment.

Guidelines for treating contractures in patients with SMA have recommended incorporating both surgical and nonsurgical management. ${ }^{14,32,36}$ There is literature to support the use of orthotic treatments and physical therapy and acknowledgement of the efficacy of tenotomy for limb contractures. ${ }^{24,36}$ Like surgical treatments for hip instability, historic strategies must be re-examined in light of functional improvement of children with SMA treated with novel therapies like nusinersen.

Due to the rapidly evolving field of micromolecular treatment, modern health practitioners will likely witness a time in which these patients lead longer lives with better function. This will impact surgical decision-making in several important ways. First, some orthopaedic deformities that are initially asymptomatic, such as hip dysplasia, could ultimately become symptomatic with expanded life span or increased motor function and activity. Children with SMA who are treated with genetic therapies have a higher functional ability than previously seen, potentially worsening the observed and experienced effects of orthopaedic ailments on activities of daily life. Finally, patients receiving treatment may be able to better physiologically tolerate surgery, making them better surgical candidates. ${ }^{8,12,37}$ To address the changing landscape of treating children with SMA, the European Neuromuscular Centre (ENMC) initiated a multidisciplinary effort to improve care for children in this population. In response, a panel of experts was assembled to develop a consensus statement on orthopaedic management of patients with SMA in the era of genetic therapy. The following are the detailed findings of the orthopaedic working group subset of the ENMC, which reflect the recommendations of the entire working group.

\section{Materials and Methods}

\section{The ENMC Orthopaedic Standard of Care Working Group}

Experts were chosen to reflect diverse treatment regimens with a variety of each individual's experience in treating children with SMA. Seventeen experts were included in the initial study distribution (15 orthopaedic surgeons and two pediatric neurologists) from seven countries in North America, Europe, and Asia (United States, Canada, France, Spain, Switzerland, Turkey and Japan). Participation was voluntary and without pay.

\section{Meeting at the Scoliosis Research Society (SRS)}

In September 2015, members of the expert panel met at the annual meeting of the Scoliosis Research Society (SRS) to brainstorm topics of interest for further investigation. As a result, 17 topics were proposed, of which 16 were used to guide the literature review (Table 1). One topic ("The role of physical and occupational therapy") was deferred due to the presence of a separate Physical Therapy/Occupational Therapy working group. 


\section{Literature Review}

An extensive review of the available literature was performed on the 16 topics proposed at SRS (Table 1). Each reviewer utilized PubMed with keywords consisting of combinations of "Spinal Muscular Atrophy" or "SMA" or "Neuromuscular" plus the topic of interest. Articles were excluded if a) less than $10 \%$ of the participants were children with SMA, b) it was not a medical intervention or review article, and c) if the article subject did not pertain to one of the 16 topics of interest. Articles were graded by Oxford Centre of Evidence-based Medicine-Levels of Evidence. ${ }^{38}$ After consensus building, a second literature search was conducted to incorporate more recent evidence surrounding the implementation and effects of emerging therapies for SMA, including nusinersen. This second literature review utilized the same keywords and inclusion criteria described above for studies published during January 2016 through March 2021.

\section{Table 1. Topics Selected by Experts at SRS Meeting}

1. Preoperative nutrition evaluation

2. Management of cervical spine pathology

3. Timing of interventions for scoliosis

4. Management of chest wall deformity

5. Perioperative pulmonary care

6. The relationship between hip and spine pathology

7. Accommodating intrathecal access in spinal instrumentation

8. Timing and rationale of intervention for hip instability

9. Soft-tissue procedures

10. The role of hip osteotomy

11. Managing osteoporosis

12. Contracture management

13. Management of hip pain following spinal surgery

14. Management of pain due to contractures

15. Spinal instrumentation device size

16. The role of salvage hip surgery

Deferred: The role of physical and occupational therapy

\section{Delphi Process}

The working group developed their statement by means of the Delphi technique, an iterative process used to identify clustered responses and generate consensus opinion. ${ }^{39,40}$ This process has been used in generating guidelines for treatment of SMA in the past by members of the larger ENMC group, and due to past successes, was recommended for all working groups. ${ }^{14}$ All questionnaires were created and distributed via an online questionnaire tool to be completed within 2-4 weeks. Responses were anonymized and results were uploaded to a secure database. All questions were analyzed and categorized to consensus ( $\geq 70 \%$ agreement) and equipoise (30\%-70\% agreement) based on the standard from the ENMC.

First Questionnaire (November 2015): Literature review results and topics of interest (Table 1) were distributed to the expert panel who were asked whether or not they "were confident in providing a best practice guideline" for each of the topics based on available literature and their knowledge of orthopaedic management of SMA.

Second Questionnaire (December 2015): Topics in which $\geq 70 \%$ of the experts were confident providing best practice guidelines were included in the second questionnaire. Each topic contained three to five open-ended questions on surgical decision-making, pertinent signs and symptoms, appropriate diagnostic tests, surgical and nonsurgical interventions, and postoperative management per the ENMC format. All questions were proposed for non-sitters (SMA1), sitters (SMA2), and walkers (SMA3/4). Thus, 16 unique questions were posed for each of the three ambulatory categories, resulting in 48 total questions. Open-ended responses were collected and analyzed for the final questionnaire.

Final Questionnaire (January 2016): Based on consensus responses to the previous questionnaire, the working group leaders formulated a final questionnaire. The final questionnaire consisted of 12 questions on spine deformity, three questions on hip instability, and two questions on contracture management, decided by 
the iterative process. Questions were multiple choice and experts were instructed to choose the best response(s) for each question.

\section{Results}

\section{Literature Review}

In the initial literature review, 81 articles were found, and 35 were included. Many of the recovered studies included outcomes related to multiple topics of interest. In the subsequent literature review, 381 studies were found and 109 met inclusion criteria.

\section{Effects of Gene Therapy on Disease Progression}

Overall, nusinersen treatment in SMA is associated with significant improvement in motor function. These benefits exist in age groups ranging from infancy to adulthood, although younger age, better baseline function, and early intervention relative to symptom onset are predictive of improvements on motor function scales. . $^{37,41-72}$ Improvements also differ based on SMN2 copy number. ${ }^{73}$ Despite functional improvement, there has been no prevention of scoliosis progression with nusinersen use alone. ${ }^{63}$ While the overall effect of nusinersen treatment on life expectancy in less severe SMA subtypes is still unknown, increased likelihood of survival over 13 months has been demonstrated with nusinersen treatment in SMA I. ${ }^{5,74}$ Patient and caregiver satisfaction with nusinersen treatment is primarily hindered by treatment administration and time commitment. ${ }^{75}$ The most common adverse effects of nusinersen treatment are attributed to lumbar puncture, such as headache, back pain, and post-lumbar puncture syndrome. ${ }^{11}$

\section{Nutritional Evaluation and Bone Quality}

Before 2016. Four studies were included. Evidence suggests that nutritional analysis of children with SMA should include nutritional intake, nutritional needs, underlying medical problems, physical examination, anthropometric measurements, body composition, and biochemical markers. ${ }^{14,76,77}$ As a result of their higher risk for osteopenia, children with SMA have an increased risk of fragility fractures. ${ }^{78}$ No studies evaluated surgical risk based on nutritional status or bone quality.

During or After 2016: Thirteen studies were included: eight on nutrition challenges, three on effects of nusinersen on nutrition, and two on bone quality. Feeding difficulties and nutrient deficiencies (such as deficiency in fatty acids, vitamin A, vitamin D, vitamin $\mathrm{K}$, folate, calcium, iron and magnesium) remain common in children with SMA. ${ }^{79-82}$ Increasing evidence shows aberrant fat distribution, fatty acid metabolism, and energy expenditure in these patients. ${ }^{81,83-85}$ As a result, individual assessment and nutrition planning are recommended. ${ }^{86}$

Nusinersen has been shown to decrease the frequency of severe malnutrition in SMA I patients. ${ }^{87}$ Increased bulbar function (e.g., bite force) after treatment with nusinersen may contribute to improved nutritional outcomes. ${ }^{88}$ It is important to note, however, that despite initial improvement following administration of nusinersen, symptoms of feeding fatigue and unsafe swallowing subsequently re-appeared in SMA I patients. ${ }^{89}$

Low bone mineral density and femur fractures are highly prevalent in all subtypes of SMA. ${ }^{90}$ Intravenous bisphosphonate has been proposed to improve bone mineral density and decrease fractures in SMA, however evidence is limited. ${ }^{91}$

\section{Spine}

Before 2016: Thirteen studies were included on the management of spinal deformity. Scoliosis is highly prevalent in children with SMA, with an incidence of $60 \%-90 \%$. Initial presentation and management begins in early childhood, with high risk for progression. ${ }^{14,19,24,26,92}$ As a result, orthotic management is recommended to slow progression until the patient is of age to undergo spinal instrumentation. ${ }^{25,93}$ Growth-friendly instrumentation (GF) and posterior spinal fusion (PSF) have been employed for surgical treatment in skeletally immature and mature patients, respectively. ${ }^{14,17-19,21,32,94}$ 
One study on magnetically controlled growing rods (MCGRs) in two patients with SMA showed improved Cobb major curve angle at 2-years of follow-up and improved postoperative pulmonary function. ${ }^{95} \mathrm{No}$ studies were found on management of cervical spine pathology in patients with SMA or on how to best accommodate intrathecal access in patients needing spinal instrumentation, though multi-segmental spine constructs have been proposed. ${ }^{21}$

During or After 2016: Twenty-nine studies were included on management of spinal deformity: two on spinal instrumentation, one on management of cervical spine pathology, and 26 on intrathecal access in complex spinal deformity or instrumentation.

MCGRs and VEPTRs continue to improve Cobb major curve angle at 2-3 years of follow-up in SMA patients with spinal deformity. ${ }^{96,97}$ In the setting of cervical spine deformity, strong instrumentation and perioperative control of abnormal involuntary movements (via botulinum toxin injection, physical therapy, muscle division technique, or intrathecal baclofen pump) have been suggested. ${ }^{98}$

Intrathecal access in patients with severe scoliosis or spine instrumentation has become increasingly relevant in the age of gene therapy. Conventional approaches to intrathecal administration are hindered by complex spinal anatomy. Therefore, SMA patients with complicated spines often require fluoroscopic, ultrasound, or CT guidance for intrathecal administration. ${ }^{99-109}$ Reservoir placement may be effective but is also associated with complications such as infection and catheter separation. ${ }^{103,108,110,111}$ Transforaminal and paramedian approaches, lumbar laminectomy, and cervical or suboccipital ports may also be attempted in complex spines. ${ }^{100,112-123}$ In some patients, intrathecal administration is still not feasible. ${ }^{102,124}$ Considering the difficulties of intrathecal injection posed by spinal instrumentation, preliminary evidence in "skipping" one or more vertebral levels at the thoracolumbar junction has demonstrated increased ease of intrathecal access with no adverse clinical events, loss of correction, or hardware failure at 4 years postoperation ${ }^{125}$ (Figure 1).

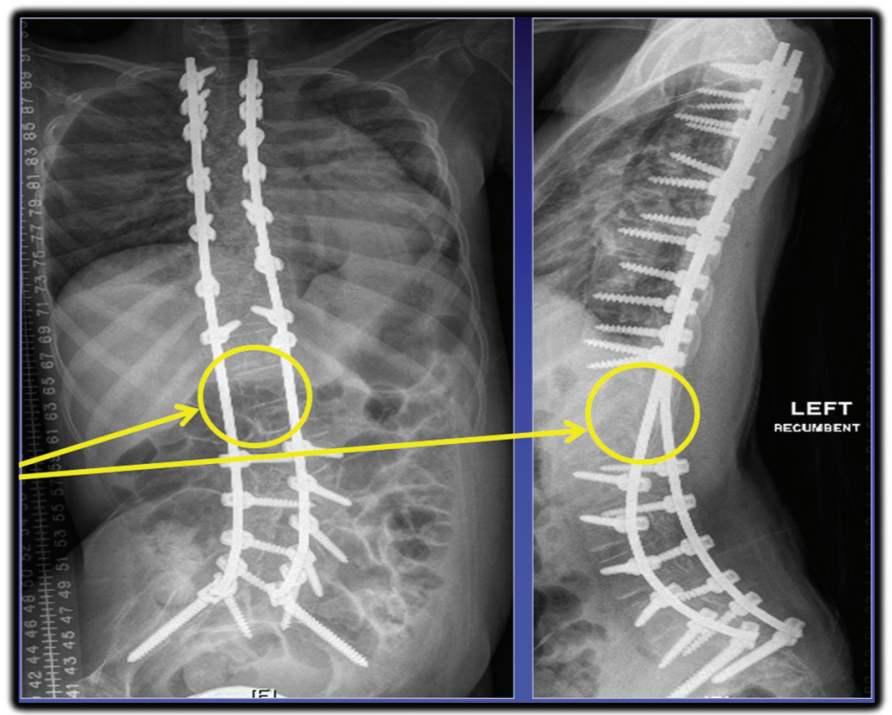

Figure 1. "Skip" construct in SMA patient requiring intrathecal therapy. L1-L2 levels not exposed (no fusion) to allow for drug delivery. ${ }^{126}$

\section{Chest Deformity, Thoracic Insufficiency, and Pulmonary Health}

Before 2016: Thirteen studies were included. Children with SMA have increased incidence of thoracic insufficiency as a result of hypotonic scoliosis and poor muscular support. ${ }^{20,32}$ As curves worsen, the deleterious effect of spine deformity on pulmonary function and lung expansion magnifies, and children with SMA have a high propensity to develop parasol rib deformities. ${ }^{20,27,28,127-129}$ Rib-based and spine-based growing instrumentation has been used to slow progression of thoracic wall collapse but has poor efficacy in increasing thoracic volume in these children. ${ }^{20}$ Poor pulmonary function should not be an absolute contraindication for spinal deformity surgery; noninvasive pulmonary support can improve pulmonary outcomes following surgery on patients with SMA. ${ }^{28,130-132}$

During or After 2016: Twenty studies on pulmonary health in SMA were included: 13 on the effect of spinal surgery on pulmonary health and seven on pulmonary outcomes of nusinersen treatment. History of pneumonia is associated with postoperative respiratory complications in neuromuscular spine deformity 
surgery. ${ }^{133}$ Still, positive outcomes are seen with scoliosis surgery even in patients with FVC of below $30 \%$ predicted. ${ }^{134}$ The effect on pulmonary function metrics after spine surgery is variable; postoperative decrease in pulmonary function (e.g., from $61.9 \%-$ $63.9 \%$ predicted FVC preoperatively to $56.3 \%-57.6 \%$ postoperatively), increase, and no change have all been reported. ${ }^{22,23,30,31,74,135-140}$ Postoperative reduction in the rate of decline of pulmonary function (e.g., from FVC decline of $5.31 \%$ per year preoperatively to $1.77 \%$ per year postoperatively) has also been described. Even with variable FVC outcomes, healthrelated quality of life pulmonary function subscores improve after growth-friendly instrumentation ${ }^{140}$ (example in Figure 2).

While nusinersen is associated with improved motor function in pediatric patients, evidence regarding the effect on pulmonary function is mixed. Nusinersen treatment has been associated with both improvement ${ }^{52,141-143}$ and no effect ${ }^{144,145}$ on lung function in various studies measured via FVC and need for assisted ventilation. Responses to nusinersen likely differ between SMN type and timing of intervention relative to symptom onset. ${ }^{142,146}$

\section{Hip}

Six studies published before 2016 were included on hip instability, a common occurrence in patients with SMA. ${ }^{14,32-35}$ Most studies recommend against surgery, as surgically repaired hips tend to progressively and continuously re-sublux, and hip pathology has rarely been shown to cause pain. ${ }^{14,33-35}$ Scoliosis and hip subluxation most often present concurrently; scoliosis may develop before hip subluxation, but hip subluxation rarely precedes scoliosis. ${ }^{147}$ No additional studies published during or after 2016 were found on the effect of genetic therapies on hip instability and hip subluxation.

\section{Contractures}

Before 2016: Seven studies were included on management of contractures. Contractures are common in patients with SMA as a result of decreased range of motion, prolonged static positioning, and agonistantagonist muscle imbalance. ${ }^{32,36,148}$ They most notably develop at the knee, elbow, hip, and ankle. ${ }^{36,149,150}$

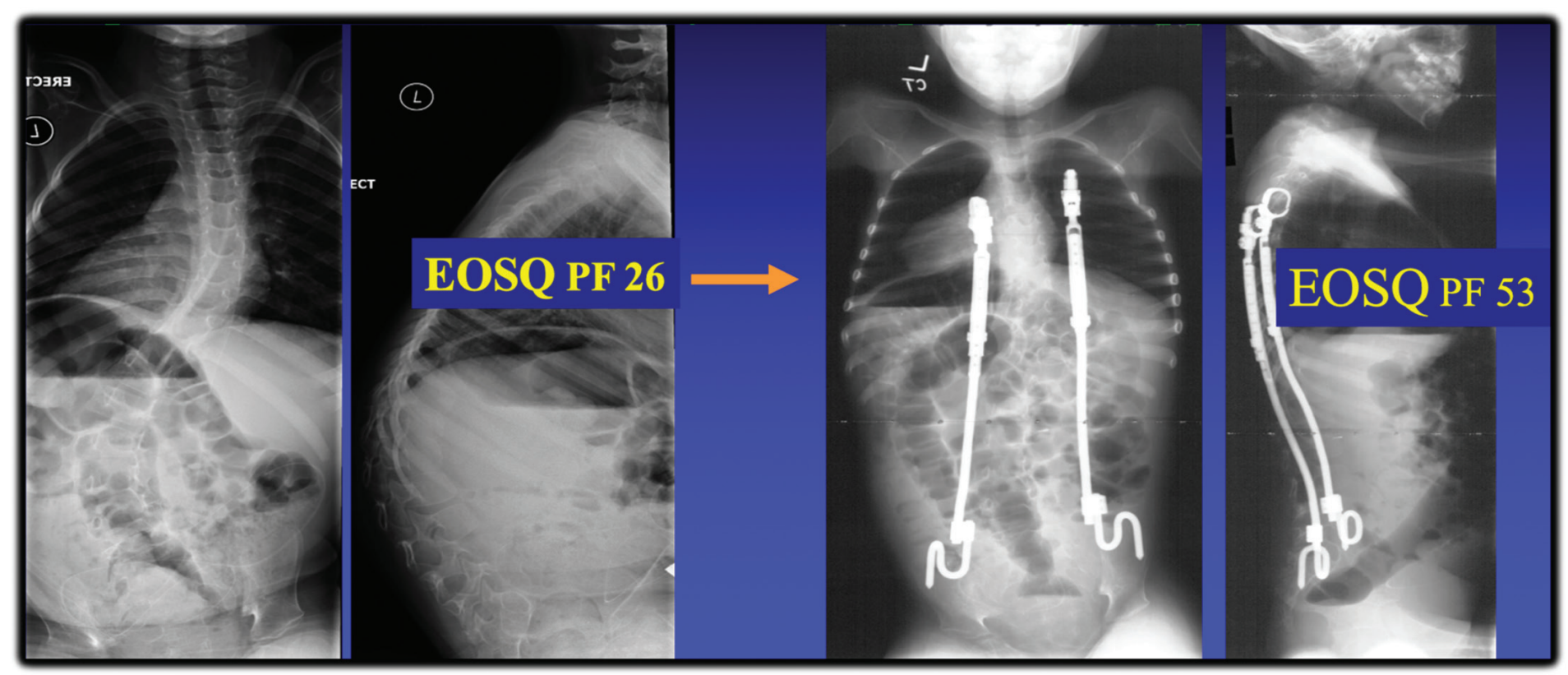

Figure 2. Pre- and postoperative radiographs of one SMA patient receiving VEPTR instrumentation. This patient demonstrated dramatically improved self-reported pulmonary function on the Early Onset Scoliosis Questionnaire (EOSQ). ${ }^{126}$ 
Functionally and symptomatically, contractures can lead to pain and inhibit function in patients with SMA. ${ }^{36,148-152}$

During or After 2016: One study was included, demonstrating that even minimal hip and knee joint contractures are associated with diminished motor ability. ${ }^{153}$ No studies were found on the effect of gene therapy on joint contractures.

\section{Delphi Process}

The ENMC Orthopaedic Standard of Care Working Group

Thirteen experts chose to participate (12 orthopaedic surgeons, one pediatric neurologist). The 13 responding experts practice in six countries in North America and Europe (United States, Canada, France, Spain, Switzerland and Turkey).

First Questionnaire Results: There were 12 expert responses - seven from North America and five from Europe. Four topics out of the 16 proposed were selected by consensus decision (>70\%) (Tables 1 and 2 ).

This survey posed 17 questions that group members then rated based on whether or not they felt that a) the question was important and b) they were confident in providing a best practice guideline in response. As a result of the first round of the process, six questions were selected:

1. Timing of spinal instrumentation

2. Management and prevention of chest wall deformity

3. Timing and rationale for intervention for hip pathology

4. Role of hip osteotomy

5. Management of contractures of upper and lower extremity

6. Surgical planning and implantation devices

Second Questionnaire Results: There were seven expert responses - four from North America and three from Europe. Responses informed the creation of the final questionnaire.
Table 2. Topics with Consensus Support for Development of an Expert Consensus Statement

1. Timing of interventions for scoliosis

2. Management of chest wall deformity

3. Timing and rationale of intervention for hip instability

4. Contracture management

Final Questionnaire Results: There were 11 expert responses - seven from North America and four from Europe. The responses from experts from the United States were not statistically significantly different from the responses from experts from Europe. The expert consensus statement was created from the answers supplied to this questionnaire (Tables 3 and 4, Figure 3).

\section{Discussion}

In light of the scientific breakthroughs in treating SMA with gene therapy, management strategies must adapt to appropriately address the changing approach for the orthopaedic care of this population. Previous studies have recommended aggressive bracing and surgical treatment of scoliosis for children with SMA. ${ }^{17-20,24-}$ 28,32,36,95,129,154 The expert consensus statement developed in this study adds to existing literature by recommending specific treatment strategies stratified by age and major curve, while also providing recommendations on interpreting accompanying characteristics such as curve progression, pain, functional changes and hyperkyphosis among other symptoms. Importantly, as genetic therapies become a mainstay of care in this population, orthopaedic treatments are recommended to accommodate intrathecal access by leaving lumbar vertebral levels un-instrumented when performing spinal surgery. In the setting of spine instrumentation or severe scoliosis, fluoroscopic, ultrasound, or CT guidance may be used for intrathecal access. Without "skip" level constructs, repeated intrathecal injection (every 4 months for the duration of life) may result in a significant cumulative radiation dose for patients and thus may present a health risk. ${ }^{104}$ In addition, promising results from early studies ${ }^{155-158}$ and the professional experience 
Table 3. Agreement with Items Describing the Treatment of SMA Reaching Consensus (>70\% in Favor or Against)

\begin{tabular}{|c|c|}
\hline Items Describing Treatment of SMA in Spine Deformity & $\begin{array}{l}\mathbf{n} / \mathbf{N}(\%) \text { in } \\
\text { Agreement }\end{array}$ \\
\hline $\begin{array}{l}\text { There is a role for orthotic bracing of spine deformity in skeletally immature patients with major curve angle between } \\
15-50^{\circ} \text {. }\end{array}$ & $9 / 11(82 \%)$ \\
\hline Spine instrumentation should be implemented in patients with major curve angle greater than $50^{\circ}$. & $10 / 11(91 \%)$ \\
\hline GF instrumentation should be used in skeletally immature patients with major curve angle greater than $50^{\circ}$. & $10 / 11(91 \%)$ \\
\hline In the setting of a large, progressive curve, GF instrumentation is appropriate at ages 4 through 8 years. & $10 / 11(91 \%)$ \\
\hline PSF should be used in skeletally mature patients with major curve angle greater than $50^{\circ}$. & $10 / 11(91 \%)$ \\
\hline In the setting of a large, progressive curve, PSF is appropriate at ages greater than or equal to 12 years. & $10 / 11(91 \%)$ \\
\hline $\begin{array}{l}\text { For children with curves greater than } 50^{\circ} \text {, between } 8 \text { and } 12 \text { years old, instrumentation depends on skeletal maturity } \\
\text { and clinical reasoning. }\end{array}$ & $10 / 11(91 \%)$ \\
\hline Curve progression is a major factor in surgical decision making in skeletally immature patients and mature patients. & $\begin{array}{l}10 / 11(91 \%) \\
9 / 11(82 \%)\end{array}$ \\
\hline $\begin{array}{l}\text { Curve progression, decreasing respiratory function, adverse effect on function, pelvic obliquity, trunk imbalance, and } \\
\text { rib parasol encourage the decision to implement spinal instrumentation. }\end{array}$ & $\begin{array}{l}8 / 11-10 / 11 \\
(73 \%-91 \%)\end{array}$ \\
\hline $\begin{array}{l}\text { Pulmonary function tests (e.g., FEV1, FVC) are important evaluation tests for patients undergoing surgery for } \\
\text { scoliosis. }\end{array}$ & $9 / 11(82 \%)$ \\
\hline $\begin{array}{l}\text { MCGRs should be used as an alternative to traditional growing rods in skeletally immature patients with SMA in order } \\
\text { to decrease the need for repeated surgery. }\end{array}$ & $10 / 11(91 \%)$ \\
\hline At skeletal maturity, GF instrumentation should be converted to PSF on a case-by-case basis. & $10 / 11(91 \%)$ \\
\hline Certain levels should be left unfused/ungrafted in spinal instrumentation constructs to accommodate intrathecal access. & $9 / 11(82 \%)$ \\
\hline Items Describing Treatment of SMA in Hip Instability & $\begin{array}{l}\mathrm{n} / \mathrm{N}(\%) \text { in } \\
\text { Agreement }\end{array}$ \\
\hline Unilateral and bilateral hip instability should be surgically managed in cases of significant pain or impaired function. & $9 / 11(82 \%)$ \\
\hline Items Describing Treatment of SMA in Contractures & $\begin{array}{l}\text { n/N }(\%) \text { in } \\
\text { Agreement }\end{array}$ \\
\hline Contractures of the lower extremity should be surgically managed when they cause pain or impair function. & $\begin{array}{l}8 / 11(73 \%) \\
11 / 11(100 \%) \\
\end{array}$ \\
\hline Contractures of the upper extremity should be surgically managed when they impair function. & $8 / 11(73 \%)$ \\
\hline
\end{tabular}

GF: growth friendly; PSF: posterior spinal fusion; FEV1: forced expiratory volume over 1 second; FVC: forced vital capacity.

of the committee members informs the recommendation for use of magnetically controlled growing rods for this population.

While nascent literature explains the historic futility in treating hip subluxation, experts overwhelmingly believe that the new therapies will decrease the incidence of both hip pathology and recurrence after repair via improved muscle tone. ${ }^{32,35}$ As a result, our consensus recommendation reflects this and advises aggressive treatment of hip instability to capitalize on the treatment's effects and allow for maximal mobility. In the same vein, previous studies on contracture management have recommended both conservative treatment such as orthoses, physiotherapy, and occupational therapy as well as interventional operations such as tendon lengthening and/or tenotomy in this population. ${ }^{24,36}$ Historic surgical contracture correction was recommended only to facilitate sitting, allow for comfortable footwear, 
Table 4. Agreement with Items Describing the Treatment of SMA Reaching Equipoise (30\%-70\% in Favor or Against)

\begin{tabular}{|l|l|}
\hline Items Describing Treatment of SMA in Spine Deformity & n/N (\%) in Agreement \\
\hline GF instrumentation may be used in skeletally immature patients with major curve angle of 40-50. & $5 / 11(45 \%)$ \\
\hline Rib-based constructs may be used to control parasol rib deformity vs. spine-based constructs. & $6 / 11(55 \%)$ \\
\hline $\begin{array}{l}\text { The decision to implement spinal instrumentation may or may not be encouraged by: back pain or } \\
\text { independent ambulation. }\end{array}$ & $\begin{array}{l}5 / 11(45 \%) \\
4 / 11(36 \%)\end{array}$ \\
\hline 2-year-old children with large progressive curves may receive GF instrumentation. & $6 / 11(55 \%)$ \\
\hline Items Describing Treatment of SMA in Hip Instability & $\mathbf{n / N ~ ( \% ) ~ i n ~ A g r e e m e n t ~}$ \\
\hline Hip osteotomy technique and approach may depend on pathology and imaging. & $7 / 11(64 \%)$ \\
\hline Items Describing Treatment of SMA in Contractures & $\mathbf{n / N}(\%)$ in Agreement \\
\hline Contractures of the upper extremity may be surgically managed when they cause pain. & $6 / 11(55 \%)$ \\
\hline
\end{tabular}

Assuming a large, progressive curve, what approach is appropriate for each given age?

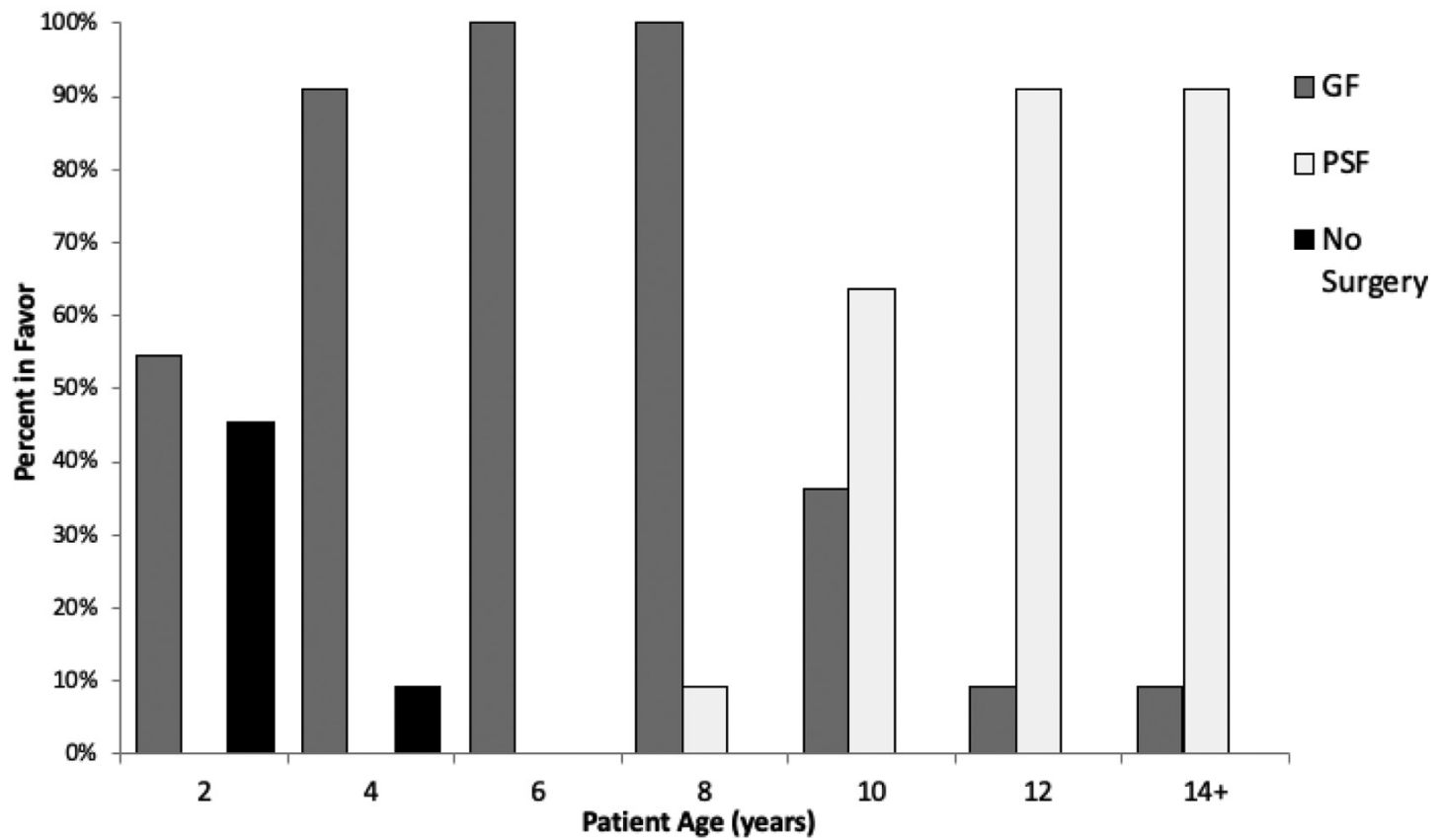

Figure 3. Expert panel recommendations regarding spine surgery in the setting of large, progressive curves in patients of varying ages.

and prevent pressure ulcers. ${ }^{32}$ In light of the changes in muscle tone as a result of new treatment options, the experts in this study recommended surgery for contractures in cases of decreased function and to correct painful contractures of the lower extremity.

We encountered some limitations in this endeavor. First, the final expert panel in this study consisted of
13 members, despite the initial 17 invitations. Though literature demonstrates that the Delphi Process can be employed with as few as 10 to 15 members, it functions optimally with 15 to 20 members. ${ }^{40}$ Second, our next questionnaire had suboptimal involvement with seven responses. As a result, fewer choices were available to include in the final questionnaire, leading to the 
possibility that essential viewpoints were omitted from further discussion. Third, physicians for this venture were selected from North America, Europe, and Asia, but ultimately only included members from North America and Europe. Future processes should involve more expert physicians from diverse backgrounds and practices across the globe.

Orthopaedic treatment for patients with SMA is perpetually changing. Contemporary analysis of patients with SMA is warranted to understand the incidence of musculoskeletal manifestations of SMA, their impact on quality of life and function, and the impact of treatments. Additionally, critical analysis of methodology is necessary to identify the best ways to select appropriate endpoints. Topics of further investigation should include the effect of gene therapy in decreasing the incidence and severity of contractures, fragility fractures, hip instability, and spinal deformity in order to fully understand the effects of this revolutionary therapy on this population. Because gene therapies continue to change the trajectory of this disease and the perception of its prognosis, we may need to revisit the Delphi process to accommodate for the many anticipated innovations in treatment for SMA in the coming years, such as the oral genetic therapy Evrysdi (risdiplam) that was approved by the FDA in August 2020.

\section{Additional Links}

- The SMA Foundation: "Since its inception in 2003, the SMA Foundation has spent around \$150M on basic, translational, and clinical research to accelerate progress towards finding a treatment for SMA.” https://smafoundation.org/research/

\section{- The Pediatric Spine Foundation: "The Pediatric} Spine Foundation is a community dedicated to improving the quality of care and the outcome of treatment for patients and families dealing with chest wall and spine deformities." https://pediatricspinefoundation.org/

\section{- POSNAcademy Webinar "The Orthopedic} Management of Spinal Muscular Atrophy: New Treatments...Next Steps," presented by Jill E. Larson, MD; John Grayhack, MD; Brian Snyder, MD, PhD*;
Amanda T. Whitaker, MD; Michael Vitale, MD https://www.posnacademy.org/media/The+Orthopedic+ Management + Spinal + Muscular + AtrophyA + New+Treatments\%E2\%80\%A6Next+Steps/1_0d4j9im6

\section{References}

1. Morris A, Creasman J, Turner J, et al. Intensive care of human immunodeficiency virus-infected patients during the era of highly active antiretroviral therapy. Am J Respir Crit Care Med. 2002;166:262-267. doi: https://doi.org/10.1164/rccm.2111025.

2. Sugarman EA, Nagan N, Zhu H, et al. Pan-ethnic carrier screening and prenatal diagnosis for spinal muscular atrophy: clinical laboratory analysis of >72 400 specimens. Eur J Hum Genet. 2012;20(1):27-32. doi: https:// doi.org/10.1038/ejhg.2011.134.

3. Butchbach MER. Copy number variations in the survival motor neuron genes: implications for spinal muscular atrophy and other neurodegenerative diseases. Front Mol Biosci. 2016;3:7. doi: https://doi. org/10.3389/fmolb.2016.00007.

4. Lunn MR, Wang CH. Spinal muscular atrophy. Lancet. 2008;371 (9630):2120-2133. doi: https://doi.org/10.1016/S0140-6736(08) 60921-6.

5. Abreu NJ, Waldrop MA. Overview of gene therapy in spinal muscular atrophy and Duchenne muscular dystrophy. Pediatr Pulmonol. 2021;56(4):710-720. doi: https://doi.org/10.1002/ppul.25055.

6. Rigo F, Hua Y, Krainer AR, Bennett CF. Antisense-based therapy for the treatment of spinal muscular atrophy. J Cell Biol. 2012;199(1):21-25. doi: https://doi.org/10.1083/jcb.201207087.

7. Zanetta C, Nizzardo M, Simone C, et al. Molecular therapeutic strategies for spinal muscular atrophies: current and future clinical trials. Clin Ther. 2014;36(1):128-140. doi: https://doi.org/10.1016/ j.clinthera.2013.11.006.

8. Corey DR. Nusinersen, an antisense oligonucleotide drug for spinal muscular atrophy. Nat Neurosci. 2017;20(4):497-499. doi: https://doi. org/10.1038/nn.4508.

9. Singh NN, Howell MD, Androphy EJ, et al. How the discovery of ISS-N1 led to the first medical therapy for spinal muscular atrophy. Gene Ther. 2017;24:520-526. Published online May 2017. doi: https://doi.org/10.1038/ gt.2017.34.

10. Wertz MH, Sahin M. Developing therapies for spinal muscular atrophy. Ann N Y Acad Sci. 2016;1366(1):5-19. doi: https://doi.org/10.1111/ nyas. 12813.

11. Hache M, Swoboda KJ, Sethna N, et al. Intrathecal injections in children with spinal muscular atrophy: nusinersen clinical trial experience. J Child Neurol. 2016;31(7):899-906. doi: https://doi. org $/ 10.1177 / 0883073815627882$.

12. Chiriboga CA, Swoboda KJ, Darras BT, et al. Results from a phase 1 study of nusinersen (ISIS-SMN(Rx)) in children with spinal muscular atrophy. Neurology. 2016;86(10):890-897. doi: https://doi.org/10.1212/ WNL.0000000000002445.

13. Walsh S. FDA Approves First Drug for Spinal Muscular Atrophy. FDA News Release. 2016.

14. Wang CH, Finkel RS, Bertini ES, et al. Consensus statement for standard of care in spinal muscular atrophy. J Child Neurol. 2007;22(8):1027-1049. doi: https://doi.org/10.1177/0883073807305788.

15. Bach JR. Medical considerations of long-term survival of WerdnigHoffmann disease. Am J Phys Med Rehabil. 2007;86(5):349-355. doi: https://doi.org/10.1097/PHM.0b013e31804b1d66.

16. Mercuri E, Mazzone ES, Montes J, et al. Spinal Muscular Atrophy Motor Functional Scales and Measures of Pulmonary Function. Spinal Muscular Atrophy. 2017:371-382.

17. Sponseller PD, Yang JS, Thompson GH, et al. Pelvic fixation of growing rods: comparison of constructs. Spine (Phila Pa 1976). 
2009;34(16):1706-1710. doi: https://doi.org/10.1097/BRS 0b013e3181ab240e.

18. McElroy MJ, Shaner AC, Crawford TO, et al. Growing rods for scoliosis in spinal muscular atrophy: structural effects, complications, and hospital stays. Spine (Phila Pa 1976). 2011;36(16):1305-1311. doi: https://doi. org/10.1097/BRS.0b013e3182194937.

19. Chandran S, McCarthy J, Noonan K, et al. Early treatment of scoliosis with growing rods in children with severe spinal muscular atrophy: a preliminary report. J Pediatr Orthop. 2011;31(4):450-454. doi: https://doi. org/10.1097/BPO.0b013e31821722b1.

20. Livingston K, Zurakowski D, Snyder B. Parasol rib deformity in hypotonic neuromuscular scoliosis: a new radiographical definition and a comparison of short-term treatment outcomes with VEPTR and growing rods. Spine (Phila Pa 1976). 2015;40(13):E780-E786. doi: https://doi. org/10.1097/BRS.0000000000000911.

21. Fujak A, Raab W, Schuh A, et al. Operative treatment of scoliosis in proximal spinal muscular atrophy: results of 41 patients. Arch Orthop Trauma Surg. 2012;132(12):1697-1706. doi: https://doi.org/10.1007/ s00402-012-1610-8.

22. Lenhart RL, Youlo S, Schroth MK, et al. Radiographic and respiratory effects of growing rods in children with spinal muscular atrophy. $J$ Pediatr Orthop. 2017;37:e500-e504. doi: https://doi.org/10.1097/ BPO.0000000000000867.

23. Nossov SB, Curatolo E, Campbell RM, et al. VEPTR: are we reducing respiratory assistance requirements? J Pediatr Orthop. 2019;39(1):28-32. doi: https://doi.org/10.1097/BPO.0000000000000986.

24. Evans G, Drennan J, Russman B. Functional classification and orthopaedic management of spinal muscular atrophy. J Bone Jt Surg Br. 1981;63B(4):516-522.

25. Catteruccia M, Vuillerot C, Vaugier I, et al. Orthopedic management of scoliosis by garches brace and spinal fusion in SMA type 2 children. J Neuromuscul Dis. 2015;2(4):453-462. doi: https://doi.org/10.3233/ JND-150084.

26. Phillips DP, Roye DP, Farcy JP, et al. Surgical treatment of scoliosis in a spinal muscular atrophy population. Spine (Phila Pa 1976). 1990;15(9):942-945.

27. Chng SY, Wong YQ, Hui JH, et al. Pulmonary function and scoliosis in children with spinal muscular atrophy types II and III. J Paediatr Child Health. 2003;39(9):673-676. Available at: http://www.ncbi.nlm.nih.gov/ pubmed/14629498.

28. Modi HN, Suh S-W, Hong J-Y, et al. Surgical correction of paralytic neuromuscular scoliosis with poor pulmonary functions. $J$ Spinal Disord Tech. 2011;24(5):325-333. doi: https://doi.org/10.1097/ BSD.0b013e3181f9f6fc.

29. Bridwell KH, Baldus C, Iffrig TM, et al. Process measures and patient/ parent evaluation of surgical management of spinal deformities in patients with progressive flaccid neuromuscular scoliosis (Duchenne's muscular dystrophy and spinal muscular atrophy). Spine (Phila Pa 1976). 1999;24(13):1300-1309. Available at: http://www.ncbi.nlm.nih.gov/ pubmed/10404571. Accessed October 6, 2015.

30. Chou S-H, Lin G-T, Shen P-C, et al. The effect of scoliosis surgery on pulmonary function in spinal muscular atrophy type II patients. Eur Spine J. 2017;26:1720-1730. doi: https://doi.org/10.1007/s00586-016-4828-2.

31. Chua K, Tan CY, Chen Z, et al. Long-term follow-up of pulmonary function and scoliosis in patients with duchenne's muscular dystrophy and spinal muscular atrophy. J Pediatr Orthop. 2016;36(1):63-69. doi: https:// doi.org/10.1097/BPO.0000000000000396.

32. Mesfin A, Sponseller PD, Leet AI. Spinal muscular atrophy: manifestations and management. J Am Acad Orthop Surg. 2012;20(6):393-401. doi: https://doi.org/10.5435/JAAOS-20-06-393.

33. Sporer SM, Smith BG. Hip dislocation in patients with spinal muscular atrophy. J Pediatr Orthop. 2003;23(1):10-14.

34. Zenios M, Sampath J, Cole C, et al. Operative treatment for hip subluxation in spinal muscular atrophy. J Bone Joint Surg Br.
2005;87(11):1541-1544. doi: https://doi.org/10.1302/0301620X.87B11.16216.

35. Thompson CE, Larsen LJ. Recurrent hip dislocation in intermediate spinal atrophy. J Pediatr Orthop. 1990;10(5):638-641.

36. Haaker G, Fujak A. Proximal spinal muscular atrophy: current orthopedic perspective. Appl Clin Genet. 2013;6(11):113-120. doi: https://doi. org/10.2147/TACG.S53615.

37. Finkel RS, Chiriboga CA, Vajsar J, et al. Treatment of infantile-onset spinal muscular atrophy with nusinersen: a phase 2, open-label, doseescalation study. Lancet. 2016;388(10063):3017-3026. doi: https://doi. org/10.1016/S0140-6736(16)31408-8.

38. OCEBM Levels of Evidence Working Group, Durieux N, Pasleau F, Howick J. The Oxford 2011 Levels of Evidence. Group. 2011;1(version):5653.

39. Brown BB. Delphi Process. Published online 1968. Available at: http:// www.rand.org/pubs/papers/P3925.html. Accessed February 22, 2016.

40. Hsu C, Sandford B. The delphi technique: making sense of consensus. Pract Assessment, Res Eval. 2007;12(10):1-8. doi: https://doi.org/10.1016/ S0169-2070(99)00018-7.

41. Pane M, Coratti G, Sansone VA, et al. Type I SMA "new natural history": long-term data in nusinersen-treated patients. Ann Clin Transl Neurol. 2021;8(3):548-557. doi: https://doi.org/10.1002/acn3.51276.

42. Wadman RI, van der Pol WL, Bosboom WM, et al. Drug treatment for spinal muscular atrophy types II and III. Cochrane Database Syst Rev. 2020;1(1):CD006282. doi: https://doi.org/10.1002/14651858.CD006282. pub5.

43. Farrar MA, Kiernan MC. Treating adults with spinal muscular atrophy with nusinersen. J Neurol Neurosurg Psychiatry. 2020;91(11):1139. doi: https://doi.org/10.1136/jnnp-2020-324036.

44. Aragon-Gawinska K, Daron A, Ulinici A, et al. Sitting in patients with spinal muscular atrophy type 1 treated with nusinersen. Dev Med Child Neurol. 2020;62(3):310-314. doi: https://doi.org/10.1111/dmcn.14412.

45. Osredkar D, Jílková M, Butenko T, et al. Children and young adults with spinal muscular atrophy treated with nusinersen. Eur J Paediatr Neurol. 2020;30(PG-1-8):1-8. doi: https://doi.org/10.1016/j.ejpn.2020.11.004.

46. Szabó L, Gergely A, Jakus R, et al. Efficacy of nusinersen in type 1, 2 and 3 spinal muscular atrophy: Real world data from Hungarian patients. Eur J Paediatr Neurol. 2020;27(PG-37-42):37-42. doi: https://doi. org/10.1016/j.ejpn.2020.05.002.

47. Maggi L, Bello L, Bonanno S, et al. Nusinersen safety and effects on motor function in adult spinal muscular atrophy type 2 and $3 . J$ Neurol Neurosurg Psychiatry. 2020;91(11):1166-1174. doi: https://doi. org/10.1136/jnnp-2020-323822.

48. Yeo CJJ, Simeone SD, Townsend EL, et al. Prospective cohort study of nusinersen treatment in adults with spinal muscular atrophy. $J$ Neuromuscul Dis. 2020;7(3):257-268. doi: https://doi.org/10.3233/JND-190453.

49. Darras BT, Chiriboga CA, Iannaccone ST, et al. Nusinersen in later-onset spinal muscular atrophy: long-term results from the phase $1 / 2$ studies. Neurology. 2019;92(21):e2492-e2506. doi: https://doi.org/10.1212/ WNL.0000000000007527.

50. Meylemans A, De Bleecker J. Current evidence for treatment with nusinersen for spinal muscular atrophy: a systematic review. Acta Neurol Belg. 2019;119(4):523-533. doi: https://doi.org/10.1007/ s13760-019-01199-Z

51. Wurster CD, Winter B, Wollinsky K, et al. Intrathecal administration of nusinersen in adolescent and adult SMA type 2 and 3 patients. $J$ Neurol. 2019;266(1):183-194. doi: https://doi.org/10.1007/s00415-018-9124-0.

52. de Holanda Mendonça R, Jorge Polido G, Ciro M, et al. Clinical outcomes in patients with spinal muscular atrophy type 1 treated with nusinersen. J Neuromuscul Dis. 2021;8(2):217-224. doi: https://doi.org/10.3233/ JND-200533.

53. Claborn MK, Stevens DL, Walker CK, et al. Nusinersen: a treatment for spinal muscular atrophy. Ann Pharmacother. 2019;53(1):61-69. doi: https://doi.org/10.1177/1060028018789956. 
54. Pane M, Coratti G, Sansone VA, et al. Nusinersen in type 1 spinal muscular atrophy: twelve-month real-world data. Ann Neurol. 2019;86(3):443-451. doi: https://doi.org/10.1002/ana.25533.

55. Montes J, Dunaway Young S, Mazzone ES, et al. Nusinersen improves walking distance and reduces fatigue in later-onset spinal muscular atrophy. Muscle Nerve. 2019;60(4):409-414. doi: https://doi.org/10.1002/ mus.26633.

56. Dangouloff T, Servais L. Clinical evidence supporting early treatment of patients with spinal muscular atrophy: current perspectives. Ther Clin Risk Manag. 2019;15(PG-1153-1161):1153-1161. doi: https://doi.org/10.2147/ TCRM.S172291.

57. de Vivo DC, Bertini E, Swoboda KJ, et al. Nusinersen initiated in infants during the presymptomatic stage of spinal muscular atrophy: Interim efficacy and safety results from the Phase 2 NURTURE study. Neuromuscul Disord. 2019;29(11):842-856. doi: https://doi.org/10.1016/j. nmd.2019.09.007.

58. Gidaro T, Servais L. Nusinersen treatment of spinal muscular atrophy: current knowledge and existing gaps. Dev Med Child Neurol. 2019;61(1):19-24. doi: https://doi.org/10.1111/dmcn.14027.

59. Pane M, Palermo C, Messina S, et al. Nusinersen in type 1 SMA infants, children and young adults: Preliminary results on motor function. Neuromuscul Disord. 2018;28(7):582-585. doi: https://doi.org/10.1016/j. nmd.2018.05.010.

60. Pechmann A, Langer T, Schorling D, et al. Evaluation of children with SMA type 1 under treatment with nusinersen within the expanded access program in germany. J Neuromuscul Dis. 2018;5(2):135-143. doi: https:// doi.org/10.3233/JND-180315.

61. Aragon-Gawinska K, Seferian AM, Daron A, et al. Nusinersen in patients older than 7 months with spinal muscular atrophy type 1: a cohort study. Neurology. 2018;91(14):e1312-e1318. doi: https://doi.org/10.1212/ WNL.0000000000006281.

62. Mercuri E, Darras BT, Chiriboga CA, et al. Nusinersen versus sham control in later-onset spinal muscular atrophy. $N$ Engl J Med. 2018;378(7):625-635. doi: https://doi.org/10.1056/NEJMoa1710504.

63. Mendonça RH, Polido GJ, Matsui C, et al. Real-world data from nusinersen treatment for patients with later-onset spinal muscular atrophy: a single center experience. J Neuromuscul Dis. 2021;8(1):101-108. doi: https://doi.org/10.3233/JND-200551.

64. Stolte B, Totzeck A, Kizina K, et al. Feasibility and safety of intrathecal treatment with nusinersen in adult patients with spinal muscular atrophy. Ther Adv Neurol Disord. 2018;11:1756286418803246. doi: https://doi. org/10.1177/1756286418803246.

65. Finkel RS, Mercuri E, Darras BT, et al. Nusinersen versus sham control in infantile-onset spinal muscular atrophy. $N$ Engl J Med. 2017;377(18):1723-1732. doi: https://doi.org/10.1056/NEJMoa1702752.

66. Chiriboga CA. Nusinersen for the treatment of spinal muscular atrophy. Expert Rev Neurother. 2017;17(10):955-962. doi: https://doi.org/10.1080/ 14737175.2017 .1364159

67. Modrzejewska S, Kotulska K, Kopyta I, et al. Nusinersen treatment of spinal muscular atrophy type 1 - results of expanded access programme in Poland. Neurol Neurochir Pol. 2021;55(3):289-294. doi: https://doi. org/10.5603/PJNNS.a2021.0020.

68. Konersman CG, Ewing E, Yaszay B, et al. Nusinersen treatment of older children and adults with spinal muscular atrophy. Neuromuscul Disord. 2021;31(3):183-193. doi: https://doi.org/10.1016/j.nmd.2020.12.006.

69. Acsadi G, Crawford TO, Müller-Felber W, et al. Safety and efficacy of nusinersen in spinal muscular atrophy: The EMBRACE study. Muscle Nerve. 2021;63(5):668-677. doi: https://doi.org/10.1002/mus.27187.

70. De Wel B, Goosens V, Sobota A, et al. Nusinersen treatment significantly improves hand grip strength, hand motor function and MRC sum scores in adult patients with spinal muscular atrophy types 3 and 4. J Neurol. 2021;268(3):923-935. doi: https://doi.org/10.1007/ s00415-020-10223-9.
71. Kim AR, Lee JM, Min YS, et al. Clinical experience of nusinersen in a broad spectrum of spinal muscular atrophy: a retrospective study. Ann Indian Acad Neurol. 2020;23(6):796-801. doi: https://doi.org/10.4103/ aian.AIAN_524 20.

72. Audic F, de la Banda MGG, Bernoux D, et al. Effects of nusinersen after one year of treatment in 123 children with SMA type 1 or 2: a French real-life observational study. Orphanet J Rare Dis. 2020;15(1):148. doi: https://doi.org/10.1186/s13023-020-01414-8.

73. Chan SH, Chae JH, Chien YH, et al. Nusinersen in spinal muscular atrophy type 1 from neonates to young adult: 1-year data from three AsiaPacific regions. J Neurol Neurosurg Psychiatry. 2021;92(11):1244-1246. doi: https://doi.org/10.1136/jnnp-2020-324532.

74. Sansone VA, Pirola A, Albamonte E, et al. Respiratory needs in patients with type 1 spinal muscular atrophy treated with nusinersen. $J$ Pediatr. 2020;219:223-228.e4. doi: https://doi.org/10.1016/j.jpeds.2019.12.047.

75. Chen E, Dixon S, Naik R, et al. Early experiences of nusinersen for the treatment of spinal muscular atrophy: Results from a large survey of patients and caregivers. Muscle Nerve. 2021;63(3):311-319. doi: https:// doi.org/10.1002/mus.27116.

76. Tilton AH, Miller MD, Khoshoo V. Nutrition and swallowing in pediatric neuromuscular patients. Semin Pediatr Neurol. 1998;5(2):106-115.

77. Iannaccone ST. Modern management of spinal muscular atrophy. J Child Neurol. 2007;22(8):974-978. doi: https://doi. org $/ 10.1177 / 0883073807305670$.

78. Vai S, Bianchi ML, Moroni I, et al. Bone and spinal muscular atrophy. Bone. 2015;79:116-120. doi: https://doi.org/10.1016/j.bone.2015.05.039.

79. Mehta NM, Newman H, Tarrant S, et al. Nutritional status and nutrient intake challenges in children with spinal muscular atrophy. Pediatr Neurol. 2016;57:80-83. doi: https://doi.org/10.1016/j. pediatrneurol.2015.12.015

80. Wadman RI, De Amicis R, Brusa C, et al. Feeding difficulties in children and adolescents with spinal muscular atrophy type 2 . Neuromuscul Disord. 2021;31(2):101-112. doi: https://doi.org/10.1016/j. nmd.2020.12.007.

81. Moore GE, Lindenmayer AW, McConchie GA, et al. Describing nutrition in spinal muscular atrophy: a systematic review. Neuromuscul Disord. 2016;26(7):395-404. doi: https://doi.org/10.1016/j.nmd.2016.05.005.

82. Zhou Y, Chen J, Gong X, et al. Nutrition status survey of type 2 and 3 spinal muscular atrophy in Chinese population. Nutr Neurosci. 2021;1-7. doi: https://doi.org/10.1080/1028415X.2020.1871212.

83. Watson KS, Boukhloufi I, Bowerman M, et al. The relationship between body composition, fatty acid metabolism and diet in spinal muscular atrophy. Brain Sci. 2021;11(2):131. doi: https://doi.org/10.3390/ brainsci11020131.

84. Li YJ, Chen TH, Wu YZ, et al. Metabolic and nutritional issues associated with spinal muscular atrophy. Nutrients. 2020;12(12):3842. doi: https:// doi.org/10.3390/nu12123842.

85. Bertoli S, De Amicis R, Mastella C, et al. Spinal muscular atrophy, types I and II: what are the differences in body composition and resting energy expenditure? Clin Nutr. 2017;36(6):1674-1680. doi: https://doi. org/10.1016/j.clnu.2016.10.020.

86. Martinez EE, Quinn N, Arouchon K, et al. Comprehensive nutritional and metabolic assessment in patients with spinal muscular atrophy: opportunity for an individualized approach. Neuromuscul Disord. 2018;28(6):512-519. doi: https://doi.org/10.1016/j.nmd.2018.03.009.

87. Yerushalmy-Feler A, Levy D, Sagi L, et al. Nutritional therapy in children with spinal muscular atrophy in the Era of Nusinersen. J Pediatr Gastroenterol Nutr. 2021;72:e154-e160. doi: https://doi.org/10.1097/ MPG.0000000000003055.

88. Kruse T, Heller R, Wirth B, et al. Maximum bite force in patients with spinal muscular atrophy during the first year of nusinersen therapy - a pilot study. Acta Myol. 2020;39(2):83-89. doi: https://doi. org/10.36185/2532-1900-010. 
89. van der Heul AMB, Cuppen I, Wadman RI, et al. Feeding and swallowing problems in infants with spinal muscular atrophy type 1: an observational study. J Neuromuscul Dis. 2020;7(3):323-330. doi: https:// doi.org/10.3233/JND-190465.

90. Wasserman HM, Hornung LN, Stenger PJ, et al. Low bone mineral density and fractures are highly prevalent in pediatric patients with spinal muscular atrophy regardless of disease severity. Neuromuscul Disord. 2017;27(4):331-337. doi: https://doi.org/10.1016/j. nmd.2017.01.019.

91. Nasomyont N, Hornung LN, Wasserman H. Intravenous bisphosphonate therapy in children with spinal muscular atrophy. Osteoporos Int 2020;31(5):995-1000. doi: https://doi.org/10.1007/s00198-019-05227-9.

92. Granata C, Merlini L, Magni E, et al. Spinal muscular atrophy: natural history and orthopaedic treatment of scoliosis. Spine (Phila Pa 1976). 1989;14:760-762. Published online 1989.

93. Fujak A, Kopschina C, Forst R, et al. Use of orthoses and orthopaedic technical devices in proximal spinal muscular atrophy. Results of survey in 194 SMA patients. Disabil Rehabil Assist Technol. 2011;6(4):305311. doi: https://doi.org/10.3109/17483107.2010.525292.

94. Anari JB, Spiegel DA, Baldwin KD. Neuromuscular scoliosis and pelvic fixation in 2015: Where do we stand? World J Orthop. 2015;6(8):564566. doi: https://doi.org/10.5312/wjo.v6.i8.564

95. Yoon WW, Sedra F, Shah S, et al. Improvement of pulmonary function in children with early-onset scoliosis using magnetic growth rods. Spine (Phila Pa 1976). 2014;39(15):1196-1202. doi: https://doi.org/10.1097/ BRS.0000000000000383.

96. Bekmez S, Dede O, Yataganbaba A, et al. Early Results of a Management Algorithm for Collapsing Spine Deformity in Young Children (Below 10-Year Old) With Spinal Muscular Atrophy Type II. J Pediatr Orthop. 2020;40(6):e413-e419. doi: https://doi.org/10.1097/ BPO.0000000000001489.

97. Hell AK, Groenefeld K, Tsaknakis K, et al. Combining bilateral magnetically controlled implants inserted parallel to the spine with rib to pelvis fixation: surgical technique and early results. Clin Spine Surg. 2018;31(6):239-246. doi: https://doi.org/10.1097/ BSD.0000000000000614

98. Lee JJ, Oh SH, Jeong YH, et al. Surgical strategies for cervical deformities associated with neuromuscular disorders. Neurospine. 2020;17(3):513-524. doi: https://doi.org/10.14245/ns.2040464.232.

99. Goedeker NL, Gibbons JL, Varadhachary AS, et al. Laboratory monitoring of nusinersen safety. Muscle Nerve. 2021;63:902-905. doi: https://doi.org/10.1002/mus.27217.

100. Weaver JJ, Natarajan N, Shaw DWW, et al. Transforaminal intrathecal delivery of nusinersen using cone-beam computed tomography for children with spinal muscular atrophy and extensive surgical instrumentation: early results of technical success and safety. Pediatr Radiol. 2018;48(3):392-397. doi: https://doi.org/10.1007/ s00247-017-4031-6.

101. Mousa MA, Aria DJ, Schaefer CM, et al. A comprehensive institutional overview of intrathecal nusinersen injections for spinal muscular atrophy. Pediatr Radiol. 2018;48(12):1797-1805. doi: https://doi org/10.1007/s00247-018-4206-9.

102. Carrera-García L, Muchart J, Lazaro JJ, et al. Pediatric SMA patients with complex spinal anatomy: Implementation and evaluation of a decision-tree algorithm for administration of nusinersen. Eur J Paediatr Neurol. 2021;31:92-101. doi: https://doi.org/10.1016/j.ejpn.2021.02.009.

103. Özütemiz C, Karachunski P, Nascene DR. Nusinersen injections in adults and children with spinal muscular atrophy: a single-center experience. Diagn Interv Radiol. 2020;26(6):596-602. doi: https://doi. org/10.5152/dir.2020.19607.

104. Spiliopoulos S, Reppas L, Zompola C, et al. Computed-tomographyguided transforaminal intrathecal nusinersen injection in adults with spinal muscular atrophy type 2 and severe spinal deformity.
Feasibility, safety and radiation exposure considerations. Eur J Neurol. 2020;27(7):1343-1349. doi: https://doi.org/10.1111/ene.14245.

105. Jacobson JP, Cristiano BC, Hoss DR. Simple fluoroscopy-guided transforaminal lumbar puncture: safety and effectiveness of a coaxial curved-needle technique in patients with spinal muscular atrophy and complex spines. AJNR Am J Neuroradiol. 2020;41(1):183-188. doi: https://doi.org/10.3174/ajnr.A6351.

106. Cordts I, Deschauer M, Lingor P, et al. Radiation dose reduction for CT-guided intrathecal nusinersen administration in adult patients with spinal muscular atrophy. Sci Rep. 2020;10(1):3406. doi: https://doi. org/10.1038/s41598-020-60240-x.

107. Cordts I, Lingor P, Friedrich B, et al. Intrathecal nusinersen administration in adult spinal muscular atrophy patients with complex spinal anatomy. Ther Adv Neurol Disord. 2020;13:1756286419887616. doi: https://doi.org/10.1177/1756286419887616.

108. Cartwright MS, Ward ZT, White EP, et al. Intrathecal delivery of nusinersen in individuals with complicated spines. Muscle Nerve. 2020;62(1):114-118. doi: https://doi.org/10.1002/mus.26899.

109. Ortiz CB, Kukreja KU, Lotze TE, et al. Ultrasound-guided cervical puncture for nusinersen administration in adolescents. Pediatr Radiol. 2019;49(1):136-140. doi: https://doi.org/10.1007/s00247-018-4240-7.

110. Iannaccone ST, Paul D, Castro D, et al. Delivery of nusinersen through an ommaya reservoir in spinal muscular atrophy. J Clin Neuromuscul Dis. 2021;22(3):129-134. doi: https://doi.org/10.1097/ CND.0000000000000333.

111. Strauss KA, Carson VJ, Brigatti KW, et al. Preliminary safety and tolerability of a novel subcutaneous intrathecal catheter system for repeated outpatient dosing of nusinersen to children and adults with spinal muscular atrophy. J Pediatr Orthop. 2018;38(10):e610-e617. doi: https://doi.org/10.1097/BPO.0000000000001247.

112. Veerapandiyan A, Pal R, D'Ambrosio S, et al. Cervical puncture to deliver nusinersen in patients with spinal muscular atrophy. Neurology. 2018;91(7):e620-e624. doi: https://doi.org/10.1212/ WNL.0000000000006006.

113. Moshe-Lilie O, Visser A, Chahin N, et al. Nusinersen in adult patients with spinal muscular atrophy: Observations from a single center Neurology. 2020;95(4):e413-e416. doi: https://doi.org/10.1212/ WNL.0000000000009914.

114. Iwayama H, Wakao N, Kurahashi H, et al. Administration of nusinersen via paramedian approach for spinal muscular atrophy. Brain Dev. 2021;43(1):121-126. doi: https://doi.org/10.1016/j.braindev.2020.07.014.

115. Weaver JJ, Hallam DK, Chick JFB, et al. Transforaminal intrathecal delivery of nusinersen for older children and adults with spinal muscular atrophy and complex spinal anatomy: an analysis of 200 consecutive injections. J Neurointerv Surg. 2021;13(1):75-78. doi: https://doi. org/10.1136/neurintsurg-2020-016058.

116. Nascene DR, Ozutemiz C, Estby H, et al. Transforaminal lumbar puncture: an alternative technique in patients with challenging access. AJNR Am J Neuroradiol. 2018;39(5):986-991. doi: https://doi. org/10.3174/ajnr.A5596.

117. Geraci AP, Black K, Jin M, et al. Transforaminal lumbar puncture for intrathecal nusinersen administration. Muscle Nerve. 2018. doi: https:// doi.org/10.1002/mus.26082.

118. Labianca L, Weinstein SL. Scoliosis and spinal muscular atrophy in the new world of medical therapy: providing lumbar access for intrathecal treatment in patients previously treated or undergoing spinal instrumentation and fusion. J Pediatr Orthop B. 2019;28(4):393-396. doi: https://doi.org/10.1097/ BPB.0000000000000632.

119. Towbin R, Schaefer C, Kaye R, et al. The complex spine in children with spinal muscular atrophy: the transforaminal approach-A transformative technique. AJNR Am J Neuroradiol. 2019;40(8):14221426. doi: https://doi.org/10.3174/ajnr.A6131. 
120. Ko D, Blatt D, Karam C, et al. Lumbar laminotomy for the intrathecal administration of nusinersen for spinal muscular atrophy: technical note and outcomes. J Neurosurg Spine. 2019:1-5. doi: https://doi. org/10.3171/2019.2.SPINE181366.

121. Bortolani S, Stura G, Ventilii G, et al. Intrathecal administration of nusinersen in adult and adolescent patients with spinal muscular atrophy and scoliosis: transforaminal versus conventional approach. Neuromuscul Disord. 2019;29(10):742-746. doi: https://doi. org/10.1016/j.nmd.2019.08.007.

122. Velayudhan V, Patel S, Danziger A, et al. Transforaminal lumbar puncture for intrathecal access: case series with literature review and comparison to other techniques. J Clin Neurosci. 2020;72:114-118. doi: https://doi.org/10.1016/j.jocn.2019.12.056.

123. Tran DK, Shah V, Muhonen MG.. Intrathecal access through suboccipital port in patients with spinal muscular atrophy and complex spines: case series and technical note. Cureus. 2020;12(8):e9525. doi: https://doi.org/10.7759/cureus.9525.

124. Veiga-Canuto D, Cifrián-Pérez M, Pitarch-Castellano I, et al. Ultrasound-guided lumbar puncture for nusinersen administration in spinal muscular atrophy patients. Eur J Neurol. 2021;28(2):676-680 doi: https://doi.org/10.1111/ene.14586.

125. Konigsberg MW, Matsumoto H, Ball JR, et al. Skip constructs in spinal muscular atrophy: outcomes of a novel approach for posterior spinal instrumentation and fusion. Spine Deform. 2020;8(5):1093-1097. doi: https://doi.org/10.1007/s43390-020-00107-3.

126. Larson J, Vitale M, Grayhack J, et al. The orthopedic management of spinal muscular atrophy: new treatments...next steps. In POSNAcademy. POSNA; 2019. Available at https://www.posnacademy. org/media/The+Orthopedic+Management+Spinal+Muscular+ AtrophyA+New+Treatments\%E2\%80\%A6Next+Steps/1_0d4j9im6.

127. Fujak A, Raab W, Schuh A, et al. Natural course of scoliosis in proximal spinal muscular atrophy type II and IIIa: descriptive clinical study with retrospective data collection of 126 patients. BMC Musculoskelet Disord. 2013;14:283. doi: https://doi.org/10.1186/1471-2474-14-283.

128. Lyager S, Steffensen B, Juhl B. Indicators of need for mechanical ventilation in Duchenne muscular dystrophy and spinal muscular atrophy. Chest. 1995;108(3):779-785.

129. Robinson D, Galasko CS, Delaney C, et al. Scoliosis and lung function in spinal muscular atrophy. Eur Spine J. 1995;4(5):268-273.

130. Mills B, Bach JR, Zhao C, et al. Posterior spinal fusion in children with flaccid neuromuscular scoliosis: the role of noninvasive positive pressure ventilatory support. J Pediatr Orthop. 2013;33(5):488-493. doi: https://doi.org/10.1097/BPO.0b013e318287058f.

131. Bach JR, Sabharwal S. High pulmonary risk scoliosis surgery: role of noninvasive ventilation and related techniques. J Spinal Disord Tech. 2005;18(6):527-530. http://www.ncbi.nlm.nih.gov/pubmed/16306844. Accessed November 2, 2015.

132. Blatter JA, Finder JD. Perioperative respiratory management of pediatric patients with neuromuscular disease. Paediatr Anaesth. 2013;23(9):770 776. doi: https://doi.org/10.1111/pan.12214.

133. Luhmann SJ, Furdock R. Preoperative variables associated with respiratory complications after pediatric neuromuscular spine deformity surgery. Spine Deform. 2019;7(1):107-111. doi: https://doi. org/10.1016/j.jspd.2018.05.005.

134. Garg S. Management of scoliosis in patients with Duchenne muscular dystrophy and spinal muscular atrophy: a literature review. J Pediatr Rehabil Med. 2016;9(1):23-29. doi: https://doi.org/10.3233/PRM-160358.

135. Alhammoud A, Othman Y, El-Hawary R, et al. The impact of scoliosis surgery on pulmonary function in spinal muscular atrophy: a systematic review. Spine Deform. 2021;9:913-921. doi: https://doi.org/10.1007/ s43390-021-00302-w.

136. Holt JB, Dolan LA, Weinstein SL. Outcomes of primary posterior spinal fusion for scoliosis in spinal muscular atrophy. J Pediatr
Orthop. 2017;37:e505-e511. Published online 2017:1. doi: https://doi. org/10.1097/BPO.0000000000001049.

137. Matsumoto M, Miyagi M, Saito W, et al. Perioperative complications in posterior spinal fusion surgery for neuromuscular scoliosis. Spine Surg Relat Res. 2018;2(4):278-282. doi: https://doi.org/10.22603/ ssrr.2017-0075.

138. Colombo L, Martini C, Bersanini C, et al. Effects of magnetically controlled growing rods surgery on pulmonary function in young subjects with spinal muscular atrophy type 2 and other neuromuscular scoliosis. J Neurosurg Sci. 2020;64(3):253-257. doi: https://doi. org/10.23736/S0390-5616.17.04052-8.

139. Farber HJ, Phillips WA, Kocab KL, et al. Impact of scoliosis surgery on pulmonary function in patients with muscular dystrophies and spinal muscular atrophy. Pediatr Pulmonol. 2020;55(4):1037-1042. doi: https://doi.org/10.1002/ppul.24664

140. Matsumoto H, Mueller J, Konigsberg M, et al. Improvement of pulmonary function measured by patient-reported outcomes in patients with spinal muscular atrophy after growth-friendly instrumentation. J Pediatr Orthop. 2021;41(1):1-5.

141. García de la Banda M, Khirani S, et al. Assessment of respiratory muscles and motor function in children with SMA treated by nusinersen. Pediatr Pulmonol. 2021;56(1):299-306. doi: https://doi.org/10.1002/ppul.25142.

142. Albrechtsen SS, Born AP, Boesen MS. Nusinersen treatment of spinal muscular atrophy - a systematic review. Dan Med J. 2020;67(9):A02200100.

143. Wadman RI, van der Pol WL, Bosboom WM, et al. Drug treatment for spinal muscular atrophy type I. Cochrane Database Syst Rev. 2019;12(12):CD006281. doi: https://doi.org/10.1002/14651858. CD006281.pub5.

144. Heitschmidt L, Pichlmaier L, Eckerland M, et al. Nusinersen does not improve lung function in a cohort of children with spinal muscular atrophy - a single-center retrospective study. Eur J Paediatr Neurol. 2021;31:88-91. doi: https://doi.org/10.1016/j.ejpn.2021.02.007.

145. Lavie M, Diamant N, Cahal M, et al. Nusinersen for spinal muscular atrophy type 1: real-world respiratory experience. Pediatr Pulmonol. 2021;56(1):291-298. doi: https://doi.org/10.1002/ppul.25140.

146. Paul GR, Gushue C, Kotha K, et al. The respiratory impact of novel therapies for spinal muscular atrophy. Pediatr Pulmonol. 2021;56(4):721-728. doi: https://doi.org/10.1002/ppul.25135.

147. Patel J, Shapiro F. Simultaneous progression patterns of scoliosis, pelvic obliquity, and hip subluxation/dislocation in non-ambulatory neuromuscular patients: an approach to deformity documentation. $J$ Child Orthop. 2015;9:345-356. Published online September 30, 2015. doi: https://doi.org/10.1007/s11832-015-0683-7.

148. Skalsky AJ, McDonald CM. Prevention and management of limb contractures in neuromuscular diseases. Phys Med Rehabil Clin N Am. 2012;23(3):675-687. doi: https://doi.org/10.1016/j.pmr.2012.06.009

149. Fujak A, Kopschina C, Gras F, Forst R, Forst J. Contractures of the lower extremities in spinal muscular atrophy type II. Descriptive clinical study with retrospective data collection. Ortop Traumatol Rehabil. 13(1):27-36.

150. Fujak A, Kopschina C, Gras F, et al. Contractures of the upper extremities in spinal muscular atrophy type II. Descriptive clinical study with retrospective data collection. Ortop Traumatol Rehabil. 12(5):410-419.

151. Carter GT, Abresch RT, Fowler WM, et al. Profiles of neuromuscular diseases. Spinal muscular atrophy. Am J Phys Med Rehabil. 1995;74(5 Suppl):S150-S159.

152. Wang HY, Ju YH, Chen SM, et al. Joint range of motion limitations in children and young adults with spinal muscular atrophy. Arch Phys Med Rehabil. 2004;85(10):1689-1693.

153. Salazar R, Montes J, Dunaway Young S, et al. Quantitative evaluation of lower extremity joint contractures in spinal muscular atrophy: implications for motor function. Pediatr Phys Ther. 2018;30(3):209215. doi: https://doi.org/10.1097/PEP.0000000000000515. 
154. Waldhausen JHT, Redding GJ, Song KM. Vertical expandable prosthetic titanium rib for thoracic insufficiency syndrome: a new method to treat an old problem. J Pediatr Surg. 2007;42(1):76-80. doi: https://doi. org/10.1016/j.jpedsurg.2006.09.059.

155. Figueiredo N, Kananeh SF, Siqueira HH, et al. The use of magnetically controlled growing rod device for pediatric scoliosis. Neurosciences (Riyadh). 2016;21(1):17-25.

156. La Rosa G, Oggiano L, Ruzzini L. Magnetically controlled growing rods for the management of early-onset scoliosis: a preliminary report. $J$
Pediatr Orthop. 2017;37:79-85. Published online July 2015. doi: https:// doi.org/10.1097/BPO.0000000000000597.

157. Dannawi Z, Altaf F, Harshavardhana NS, et al. Early results of a remotelyoperated magnetic growth rod in early-onset scoliosis. Bone Joint J. 2013;95-B(1):75-80. doi: https://doi.org/10.1302/0301-620X.95B1.29565.

158. Cheung KM-C, Cheung JP-Y, Samartzis D, et al. Magnetically controlled growing rods for severe spinal curvature in young children: a prospective case series. Lancet (London, England). 2012;379(9830):1967-1974. doi: https://doi.org/10.1016/S0140-6736(12)60112-3. 